\title{
MONOGRAPHIES DES VILLES ET VILLAGES DE FRANCE
}

Monographies des villes et villages de France est une association culturelle, à but non lucratif, dont les objectifs apparaissent clairement définis dans ses statuts : "l'exhumation, la promotion et la diffusion » d'ouvrages d'histoire locale et régionale, publiés pour la plupart dans la prestigieuse collection du même nom (M.V.V.F.) qui totalise plus de 1500 titres parus à ce jour, correspondant à des agglomérations de toute taille et de toute situation géographique.

Nous sommes d'autant plus fiers d'évoquer ces réalisations en ce début d'année 1995, que de nombreux chercheurs, dans toutes les régions de France, ont décidé de nous apporter leur soutien actif : universitaires, érudits locaux, membres de sociétés savantes, que nous avions contactés, au cours de l'automne demier, parce qu'ils nous apparaissaient les plus représentaiffs du dynamisme culturel contemporain dans le domaine qui nous intéresse, ceiui de la monographie historique.

Nous conservons deux orientations principales dans le choix de nos publications : tout d'abord la réédition d'ouvrages de qualité qui sont devenus introuvables pour le public et dont la richesse documentaire, loin d'être obsolète aujourd'hui, peut nourrir abondamment les lecteurs de notre temps; et ensuite, naturellement, la publication d'œuvres inédites qui nous montrent que le genre monographique est toujours prisé et pratiqué et qu'il reste le lien le plus fort, historiquement parlant, entre le passé et le présent, la culture et la vie, la collectivité et les chercheurs isolés.

Mais ce ne sont pas seulement ces faits culturels en eux-mêmes que nous jugeons essentiels et stimulants, c'est aussi la coalition de talents et de bonnes volontés à l'origine de leur éclosion qui nous paraît importante et porteuse d'espoir, car elle regroupe autour de la même finalité les auteurs des ouvrages concemés, les collaborateurs de l'association éditrice, les archivistes et les bibliothécaires, les chercheurs inlassables et les mécènes pour la promotion du savoir.

Cela nous montre que la connaissance du passé nous est indispensable aujourd'hui plus que jamais, pour comprendre l'état actuel de notre société, que nos concitoyens en sont parfaitement conscients et que nous ne devons pas nous contenter de faire en sorte que ces publications soient possibles, mais aussi qu'elles soient vécues par les collectivités comme des événements (civiques) déterminants. C'est ce que nous avons entrepris avec succès jusqu'à présent et c'est ce que nous continuerons à faire avec la même ardeur et le même acharnement.

Pour toutes informations :

François RJCHARD

Le fief Lorisse - 6, rue du Moulin - 02250 Autremencourt

Tél. : 23208495 Fax : 23205201 